\title{
O ENSINO MÉDIO NO BRASIL E NA FRANÇA: CONSIDERAÇÕES SOBRE A LEI 13.415/2017 A PARTIR DE UMA ANÁLISE COMPARATIVA
}

\author{
BACHILLERATO EN BRASIL Y FRANCIA: CONSIDERACIONES SOBRE LA LEY \\ 13.415/2017 A PARTIR DE UN ANALISIS COMPARATIVO
}

\author{
HIGH SCHOOL IN BRAZIL AND FRANCE: CONSIDERATIONS ABOUT THE LAW \\ 13.415/2017 THROUGH A COMPARATIVE ANALYSIS
}

\author{
Mike Ceriani de Oliveira GOMES ${ }^{1}$ \\ Mônica Galhego SAMPAIO ${ }^{2}$
}

RESUMO: Este artigo visa analisar a propaganda da lei 13.415/2017 de reforma curricular do ensino médio brasileiro, baseada em modelos de países centrais. Foi realizada uma análise comparativa entre o sistema de ensino Brasileiro e o Francês, focando o ponto mais polêmico da reforma: a oferta do ensino técnico, conflitante com o currículo formativo para o acesso ao ensino superior. Percebemos também algumas distorções no modelo proposto pela lei 13.415/2017 no que se refere ao ingresso ao ensino técnico como via de inserção imediata ao mercado de trabalho e o modelo francês que mais se aproxima deste modelo, o Baccalauréat Professionnel, certificação adquirida no Ensino Médio francês (Lycée) para ingresso ao ensino superior em áreas de formação profissional.

PALAVRAS-CHAVE: Lei 13.415/2017. Ensino Médio brasileiro. Ensino Médio francês.

RESUMEN: Este artículo objetiva analizar la propaganda de la ley 13.415/2017 para la reforma curricular en la educación secundaria brasileña, con base en modelos de países desarrollados. Realizamos un análisis comparativo entre el sistema educativo brasileño y francés, centrándonos en el punto más controvertido de la reforma: la oferta de educación técnica, en conflicto con el currículo formativo para el acceso a la educación superior. También notamos algunas distorsiones en el modelo propuesto por la ley 13.415/2017 con respecto al ingreso a la educación técnica como medio de inserción inmediata en el mercado laboral y el modelo francés que más se acerca a este modelo, el Baccalauréat Professionnel, certificación adquirida en el secundário francés (Lycée) para la admisión a la educación superior en áreas de formación profesional.

PALABRAS-CLAVE: Ley 13.415/2017. Secundario brasileño. Secundario francés.

${ }^{1}$ Universidade Estadual Paulista (UNESP), Marília - SP - Brasil. Mestrando do Programa de Pós-Graduação em Educação. ORCID: https://orcid.org/0000-0002-7039-1137. E-mail: mikegd1@hotmail.com

${ }^{2}$ Universidade Estadual Paulista (UNESP), Marília - SP - Brasil. Mestranda do Programa de Pós-Graduação em Educação. ORCID: https://orcid.org/0000-0002-4300-1164. E-mail: monigalhego@bol.com.br 
ABSTRACT: This article aims to analyze the propaganda of Law 13.415/2017 on the curriculum reform of Brazilian high school based on models of developed countries. A comparative analysis was carried out between the Brazilian and French educational systems, focusing on the most controversial of the reform: the offer of technical education, conflicting with the formative curriculum for access to higher education. It was also realized that in the model proposed by law 13.415/2017 with regard to entry to technical education as a way of immediate insertion into the labor market and the French model that is closest to the Brazilian's, the Baccalauréat Professionnel, certification offered in the French High School (Lycée) for admission to vocational higher education in professional qualification fields.

KEYWORDS: Law 13.415/2017. Brazilian high school. French high school.

\section{Introdução}

O ano de 2016 foi intensamente marcado por inquietação na educação pública brasileira. Dentre os maiores destaques está o impeachment da então presidenta Dilma Rousseff, que em agosto teve que passar o poder ao seu vice, Michel Temer, até o cumprimento do mandato presidencial (2015-2018). Com uma passagem turbulenta pelo governo, Temer promoveu diversas reformas, sobretudo econômicas e educacionais. Em fevereiro de 2017, Temer sancionou a Lei 13.415/2017, responsável por alterações nas Diretrizes e Bases da Educação Nacional, com reformas substanciais no Ensino Médio mediante nova organização curricular (PIOLLI; SALA, 2021).

Dentre as principais justificativas, o Ministério da Educação acrescentou a necessidade de modernização do Ensino Médio, objetivando um modelo curricular cujos moldes fossem influenciados pelos de nações desenvolvidas, tais como Finlândia, Coreia do Sul, Austrália, Inglaterra, Portugal e França (FERRETI; SILVA, 2017). Passou-se a discutir amplamente a organização das disciplinas e cargas horárias no currículo escolar, bem como a oferta dos ensinos técnico e profissionalizante em complementariedade às disciplinas da base nacional comum. Hernandes (2019) formula sua crítica a este modelo a partir da intencionalidade velada de atender a interesses de um sistema estrutural de dominação, de modo a expandir desigualdades ao preparar as camadas sociais mais abastadas ao conhecimento científico e outros grupos menos privilegiados para o mercado de trabalho. $\mathrm{O}$ autor enfatiza que

Os sistemas de ensino deverão compor e organizar parte do currículo segundo a relevância que atribuam aos arranjos curriculares e suas possibilidades na oferta. Inviabiliza-se, assim, a constituição de um Sistema Nacional de Educação (SNE), aprovado pelo Plano Nacional de Educação do decênio 2014 a 2024, para o Ensino Médio, pois, excetuando-se as disciplinas de português e matemática, nos três anos, e inglês em pelo menos um ano, o currículo será organizado e composto pelos sistemas de ensino 
como melhor thes aprouver. Essa medida favorece a desigualdade nas escolas, pois quatro arranjos curriculares são idênticos aos da BNCC: linguagens e suas tecnologias, matemática e suas tecnologias, ciências da natureza e suas tecnologias, ciências humanas e sociais aplicadas. No entanto, a quinta opção, formação técnica e profissional, nada tem a ver com os conteúdos escolares. Escolas com maior poder aquisitivo, notadamente as particulares, poderão oferecer os quatro arranjos curriculares similares à BNCC, ou seja, os conteúdos escolares, que inclusive constituem a base para os processos seletivos para acesso ao ensino superior, bem como conteúdos básicos para a permanência dos estudantes nessa modalidade de ensino (HERNANDES, 2019, p. 6-7).

Um dos pontos fundamentais da argumentação, parcialmente passivo de críticas, é a questão conjuntural ao propor uma modernização do modelo educacional brasileiro partindo de sistemas já modernizados, cujas nações oferecem maior suporte social para expandir opções de curso do ensino médio. Frente à condição de desenvolvimento, que distancia o Brasil das nações mencionadas, é necessário esclarecer que esta análise não negligencia ferramentas disponíveis aos estudos de educação comparada, tais como aponta Franco (1992 apud BRANDÃO, 2019) sobre as individualidades e processos históricos dos países tomados como objetos de estudo. Contudo, é válido que este mesmo critério de análise não se sobressaia às críticas que circundam as condições materiais que distanciam tais objetos, o que possibilita, complementarmente, uma avaliação dos sujeitos de interesse do chamado Novo Ensino Médio brasileiro.

Para propósito de análises comparativas, foram selecionados os sistemas de ensino médio brasileiro, considerando seus novos moldes a partir da implementação da Lei 13.415/2017 e o modelo Francês, que também mostra similaridades e diferenças de atrativas observações. Paralelamente às questões técnicas dos dois sistemas analisados, busca-se também averiguar aspectos de desenvolvimento humano das duas nações, a fim de clarificar críticas aos agentes de interesse do Novo Ensino Médio. Esta segunda investigação apresenta como fundamento a necessidade de uma avaliação das condições materiais que possam, eventualmente, distanciar o Brasil dos êxitos obtidos no ensino médio francês ou nos outros países mencionados.

Como será mostrado no decorrer deste texto, Brasil e França contam com similaridades e especificidades. Dentre as similaridades, fora do aspecto educacional, destacam-se as populações de cada país, em seus respectivos contextos geográficos, sendo Brasil o segundo país mais populoso das Américas, atingindo 213.168.118 habitantes (IBGE, 2021) e França o mais populoso do ocidente europeu, contando com 67.422.241 habitantes (POPULATION DATA, 2021). Os mesmos órgãos citados também apontam que as duas 
nações aqui propostas para análises ocupam posição privilegiada no ranking econômico dos países com maior Produto Interno Bruto em suas respectivas regiões geográficas, sendo o Brasil o segundo maior das Américas, atrás apenas dos Estados Unidos da América. A França é o terceiro maior da Europa e está atrás apenas do Reino Unido (segundo colocado) e da Alemanha (primeira colocada). Quanto ao nível educacional, propomos uma análise sobre o ensino médio, considera-se a esse contexto questões conjunturais.

\section{O Ensino Médio no Brasil}

A educação brasileira é regida pela Lei das Diretrizes e Bases da Educação Nacional, a LDB (BRASIL, 1996). Nesta lei, o sistema educacional brasileiro está classificado em dois níveis principais: básico e superior. O Ensino Básico conta com três modalidades, sendo educação pré-escolar (4-6 anos, não obrigatória) o ensino fundamental (mínimo de nove anos de duração, obrigatório) e o ensino médio (mínimo de três anos de duração, obrigatório). O nível superior é de caráter facultativo, e tem em suas modalidades a graduação, e a pósgraduação (dividida em Lato Sensu, para cursos de especialização, aperfeiçoamento e capacitação profissional; e Stricto Sensu, para programas de mestrado e doutorado).

A LDB fixa em seu texto original que o ingresso ao ensino superior está condicionado à conclusão do ensino médio, subsequente à aprovação em processo seletivo. Estes processos seletivos basicamente contemplam provas de conhecimentos gerais e específicos, podendo variar sua elaboração de acordo com cada instituição. Tal contexto fica mais claro de ser observado nas instituições privadas, em virtude da adaptação para receber ingressantes que muitas vezes não contaram com uma boa preparação no ensino médio visando o ingresso ao ensino superior público. Dessa maneira, as instituições privadas de ensino superior também contam com mais ingressantes (MOREIRA; MOREIRA; SOARES, 2018).

Contudo, a responsabilidade do ensino médio no Brasil não está meramente limitada à "[...] formação ética e o desenvolvimento da autonomia intelectual e do pensamento crítico", como disposto na Seção IV - Do Ensino Médio da LDB (1996), levando em conta que a aprovação no processo seletivo pode não estar diretamente vinculada a esses critérios formativos. Esta desconexão entre a formação e a preparação no ensino médio público para o acesso ao ensino superior público permite a Moreira, Moreira e Soares (2018, p. 148) concluírem que há necessidade de "[...] ajustes no que concerne à organização, gestão e financiamento dessa modalidade de ensino, o que converge para a democratização do acesso à educação superior". 
Esta preocupação torna cada vez mais evidente o interesse para com melhorias no ensino médio e no acesso ao ensino superior. Em termos mais técnicos, a LDB divide o ensino médio em três anos, nos quais se procura manter toda sua proposta na formação do indivíduo, bem como a capacitação para a submissão aos processos seletivos de instituições de nível superior. Concomitantemente a este modelo, educacional observa-se que instituições mais tradicionais contam com a oferta do ensino técnico e profissionalizante, cujo foco está na preparação do indivíduo para o mercado de trabalho (CORREAA; GARCIA, 2018). A modalidade de ensino técnico e profissional é essencialmente ministrada nas Escolas Técnicas Estaduais, as ETECs, tendo ganhado maior protagonismo a partir das reformas propostas ao Ensino Médio.

É importante destacar que tradicionalmente o ensino médio tem como uma de suas funções a preparação aos processos seletivos para ingresso às instituições de ensino superior, sobretudo as públicas, independente do critério de elaboração desses processos. Dados do Censo da Educação Superior (2019) apontam que só em 2019 as matrículas em cursos de graduação correspondem a 75,8\% (6.523.678 alunos) em instituições privadas e 24,2\% (2.080.146 alunos) em instituições públicas. Ao levar em conta os alunos que aderem às instituições de ensino superior a partir da formação em ensino médio. Peduzzi (2020) aponta que a taxa de alunos ingressantes nas instituições de ensino superior privado no ano anterior é de $68,5 \%$ de estudantes vindos do ensino médio público e $31,5 \%$ do privado, ao passo que o ensino superior público conta com o ingresso de $60,1 \%$ de estudantes do ensino médio público e 39,9\% do privado. Além disso, em cursos de graduação de instituições federais, “[...] no mínimo 50\% (cinquenta por cento) de suas vagas para estudantes que tenham cursado integralmente o ensino médio em escolas públicas", segundo a Lei 12.711/12 (BRASIL, 2012).

A Lei $12.711 / 12$ é uma política pública de cotas que tem por objetivo principal a redução de inequidades materiais e raciais inerentes ao sistema escolar excludente, que por tendência favorece a população branca e de maiores condições materiais para o acesso ao ensino superior público, grupo este cuja preparação se dá em instituições privadas de ensino médio e pré-vestibular (MELERO et al., 2018).

O déficit de ingressantes do ensino médio público ao ensino superior foi tomado como justificativa para a realização de parcerias público-privadas, com a finalidade de garantir o acesso a instituições privadas por meio de programas de financiamento estudantil, tais como o FIES, cobrindo mensalidades de determinados cursos cujas universidades são vinculadas ao programa, podendo o estudante saná-las posteriormente à sua conclusão (ROSAR, 2011). 
Uma das discussões aqui propostas sobre o Novo Ensino Médio é como este pode influenciar a mediação entre ensino médio público e privado e o acesso ao ensino superior público e privado a partir de uma perspectiva classista, a mesma utilizada para compreender como se dá tal dinâmica no sistema francês.

\section{O Ensino Médio na França}

As principais reformas estruturais que deram base à administração da educação como é conhecida hoje na França perpassa a Revolução Francesa (1789-1799) e o fím do absolutismo, ganhando também influência do pensamento iluminista, ascendente em território europeu. Esses eventos, sucedidos por diversas lutas sociais, resultam na promulgação da lei de 28 de junho de 1833, estabelecendo, entre outras coisas, a obrigatoriedade e gratuidade do acesso à escola. Sendo dever do estado o fornecimento de pelo menos uma escola de ensino básico para cada comuna francesa, podendo ser mais escolas de acordo com seu número de habitantes (CONCEIÇÃO, 2020).

Conforme ocorriam os avanços e reformas administrativas no sistema francês de educação, muitas medidas foram tomadas não apenas focando resultados de cunho qualitativo, mas também fatores como permanência estudantil, uma vez que, mesmo que garantida a gratuidade e obrigatoriedade, a evasão escolar perpetuou-se em níveis preocupantes até os últimos anos do século seguinte (PROST, 2004).

Em termos estruturais, o sistema educacional francês é dividido em École Maternelle (para crianças de 2 a 5 anos de idade); École Primaire (similar ao ensino primário, ou fundamental I no Brasil em sua última configuração - primeiro ao quinto ano); Collège (similar ao ginásio, ou fundamental II no Brasil em sua última configuração - sexto ao nono ano); o Lycée (o ensino médio, dividido em três níveis: Seconde, Première e Terminale e agrupa a população de 15 a 18 anos) e a Université, o ensino superior (FRANCE, 2012).

Os estudantes no último ano do nível Lycée (terminale) prestam o chamado Baccalauréat, desenvolvido em 1808 por Napoléon Bonaparte, muito similar ao Exame Nacional do Ensino Médio, o ENEM. Trata-se de um exame de realização oral e escrita e é dividido em três diferentes formatos, a ser escolhido um de acordo com o interesse de cada estudante: o Baccalauréat Général, cuja obtenção atesta capacidade sólida para o ingresso ao ensino superior chamado pelos franceses de La licence (similar ao bacharelado e à licenciatura no modelo brasileiro); o Baccalauréat Technologique, que corresponde aos cursos na área tecnológica; e o Baccalauréat Professionnel, cujo foco é a preparação do 
estudante para o mercado de trabalho. A escolha por cada Baccalauréat determina o que vai ser cursado por cada estudante no último ano do Lycée, de modo a garantir sua preparação para a realização do exame e, por conseguinte, seu ingresso ao ensino superior (FRANCE, 2012).

É de fundamental importância também esclarecer que o ano terminale tem caráter preparatório para esses três exames, não constituindo necessariamente, de acordo com o Ministério da Educação francês, a preparação direta para o mercado de trabalho, ainda que na modalidade preparatória para a obtenção da certificação Baccalauréat Professionnel. "A criação deste diploma teve como objetivo oferecer aos alunos reprovados no ensino geral um percurso que lhes permitisse continuar a sua escolaridade, manter o índice de saídas antecipadas do sistema e permitir o acesso ao nível de bacharelado" (GENDRON, 2008, p. 8, tradução nossa).

Dados do Ministério do Ensino Superior, Pesquisa e Inovação (2019) da França apontam que o acesso ao ensino superior por intermédio do certificado Baccalauréat no ano de 2019 correspondeu a $62,8 \%$ do total de 1.675 .100 estudantes ingressantes neste período, dos quais $87 \%$ se concentravam no lycée público e $13 \%$ no privado. Vale esclarecer que a diferença na relação entre o lycée público e o privado, assim como no cenário brasileiro, também reflete em maior acesso a vagas em termos quantitativos e qualitativos na França, ou seja, por tendência o acesso ao ensino privado no lycée terminale acompanha maiores e melhores oportunidades de ingresso ao ensino superior.

[...] a questão da "eficiência" do privado em relação ao público nas trajetórias dos alunos surge no que diz respeito às desigualdades sociais de sucesso e não apenas às desigualdades sociais de acesso. Se as lacunas brutas de desempenho parecem vantajosas para o setor privado (70\% obtêm um Baccalauréat Général ou Baccalauréat Technologique em comparação com $59 \%$ dos alunos públicos) as diferenças diminuem e se limitam ao primário quando raciocinamos sobre alunos tornados comparáveis pelo controle individual (PELLET, 2012, p. 187-188, tradução e grifos nossos).

Contudo, a França também conta com políticas públicas de acesso ao ensino superior, sendo tais políticas muito similares às brasileiras. Coulon (2017) recorda que desde 2008 as universidades federais francesas adotaram um programa de reestruturação administrativa do ensino superior, o Programme de Restructuration et d'Expansion des Universités Fédérales (REUNI), cujas finalidades englobam a adoção de cotas étnicas raciais e sociais para estudantes do lycée publique; o Examen National de l'Enseignement Moyen (ENEM) como alternativa à busca pelo Baccalauréat em seu modelo tradicional, beneficiando estudantes do 
lycée público; a expansão do número de vagas e universidades às cidades interioranas, distantes das metrópoles francesas.

\section{A aplicabilidade da lei 13.415/2017}

Muitas questões precisam ser postas antes de dizer até que ponto é válida a propaganda do Governo Federal quando faz referência aos modelos educacionais das nações desenvolvidas citadas.

Primeiramente, é preciso retomar o modelo técnico na educação francesa no Ensino Médio (lycée). Não se trata de um modelo profissionalizante, preparatório para o ingresso direto ao mercado de trabalho, mas ao ensino superior com propostas de cursos voltadas à educação profissional e, de maneira geral, setores administrativos. No caso da Lei 13.415/2017, o primeiro inciso do $6^{\circ}$ parágrafo do Art. 36 diz que "a inclusão de vivências práticas de trabalho no setor produtivo ou em ambientes de simulação, estabelecendo parcerias e fazendo uso, quando aplicável, de instrumentos estabelecidos pela legislação sobre aprendizagem profissional", a materialização dessa possibilidade seria concretizada, de acordo com o segundo inciso, mediante "[...] concessão de certificados intermediários de qualificação para o trabalho, quando a formação for estruturada e organizada em etapas com terminalidade". Em suma, o ensino médio por si só seria o intermediário entre o estudante e o mercado de trabalho, não aos cursos de nível superior que apresentam essa proposta. Evidentemente, esta análise se limita ao modelo francês, entretanto, destaca-se a falta desse adendo na propaganda midiática.

Não seria incorreto dizer que esse debate ocupa destaque no sistema francês. $\mathrm{O}$ ensino profissionalizante em ambiente escolar ocorre sutilmente, não sendo pelo Baccalauréat Professionnel, como lembra Gendron (2008). Contudo, muito se discutiu essa titulação como intermediária ao mercado de trabalho. Treze anos após a publicação de seu artigo, tal reforma não foi aprovada, partindo de críticas que ganham força com índices de evasão escolar no ensino superior profissional em virtude da adesão à carreira profissional posteriormente à conclusão do ensino médio.

Sendo o Baccalauréat Professionnel uma das qualificações exigidas para o acesso ao ensino superior, essa possibilidade deve ser adaptada de forma a garantir os mesmos direitos a todos e a criar uma real efetividade das possibilidades de acesso e sucesso. Este último é particularmente importante do ponto de vista da aprendizagem ao longo da vida. No entanto, para que o Baccalauréat Professionnel continue a ser um diploma com vocação para a integração, a prossecução dos estudos imediatamente após a formatura deve 
permanecer propriedade de uma minoria, sem, por isso, fechar a porta a estudos futuros. (GENDRON, 2008, p. 17, tradução e grifos nossos)

É nesse aspecto que a discussão sobre a ampliação de ofertas de ensino médio técnico também deve pautar os impactos em cursos de ensino superior que apresentam correlações com os oferecidos pelo ensino técnico. Ainda que por um lado a expansão da oferta ao ensino técnico possa reduzir o interesse por cursos de ampla adesão, como Administração, Contabilidade e Negócios (BARROS, 2015) em instituições de ensino superior de baixa qualidade, não é possível esperar uma mudança comportamental no que se refere ao interesse por novas possibilidades de ensino superior, uma vez que o ensino médio técnico já estaria oferecendo maior acesso a formações de titulações menores, porém, mais acessíveis, algo similar à experiência francesa.

É importante reafirmar a adversidade da evasão do ensino superior, muitas vezes justificada pela necessidade de inserção imediata no mercado de trabalho, experiência vivenciada tanto na França (GENDRON, 2008) quanto no Brasil (BARROS, 2015). Tal inserção em ambos os casos se justificam pelas condições financeiras desfavoráveis no que se refere ao pagamento das mensalidades, quando se trata de instituições privadas no Brasil ou instituições públicas e privadas na França para estudantes de baixa renda que não obtêm isenções de mensalidades e benefícios dos programas de incentivo ao estudante. Dessa maneira, tanto no Brasil quanto na França, um modelo de ensino médio que venha a intermediar o ingresso do estudante diretamente ao mercado de trabalho assume, acima de tudo, uma função assistencialista.

Outro ponto importante a ser discutido remete aos grupos de interesses em esfera pública que prezam pela implementação da Lei 13.415/2017. Não foi encontrada na revisão uma justificativa a que se faça referência a partir do incentivo ao Baccalauréat Professionnel na França e, além disso, não há um modelo de ensino médio técnico com abrangência curricular passível de comparação com o brasileiro. Se tomado como um exemplo o Baccalauréat Professionnel, que tem por finalidade a formação no ensino médio para ingresso ao curso superior profissionalizante, a justificativa já apresentada por Gendron (2008) vem ganhando força nos dados estatísticos, que além de ter uma preferência muito baixa, conta com maior interesse de estudantes de classe operária e menos privilegiados (METTETAL, 2020). A experiência brasileira assemelha-se à francesa no que diz respeito ao público-alvo de áreas profissionalizantes de curso superior. Contudo, a supressão de campos de interesse de maior demanda no Brasil ocorre de maneira diferente, por formações de titulação inferior (ensino técnico) ou profissionalizantes de curta duração. 
Junto aos fatores técnicos desta análise também é necessário observar interesses que podem ser classificados como de cunho ideológico, muito perceptível através do afrouxamento curricular para a atuação docente nesse novo modelo, uma vez que novas demandas surgiriam, e consigo, a necessidade do atendimento de diversas áreas para as quais não há uma cifra satisfatória de professores com formações específicas, ou seja, há um revés logístico cuja solução apresentada pelo Governo Temer está em remanejar profissionais da educação ao invés de investir em formação, o que diretamente acarreta na precarização do trabalho e na qualidade do ensino (FERRETTI, 2018).

A reestruturação curricular proposta pela Lei 13.415/2017, ainda sobre uma análise comparativa ao modelo francês, é passível de críticas quando objetiva conduzir o processo educativo considerando a “[...] condução das 'vocações' e 'escolhas' dos estudantes" (FURTADO; SILVA, 2020, p. 173), visto que as competências adquiridas no ensino médio não necessariamente seriam aproveitadas em um exame de admissão ao ensino superior como ocorre com o aproveitamento do certificado Baccalauréat, à parte de que, como já mencionado, o ensino técnico-profissionalizante tampouco tem por objetivo mediar o ingresso do aluno ao ensino superior e, se assim fosse, a menos que as taxas de ingresso de alunos desprivilegiados às cadeiras mais disputadas dos cursos de caráter profissionalizante aumentassem a níveis satisfatórios, essa alternativa, se muito, ampliaria a demanda pelos cursos que já têm forte adesão por parte de estudantes menos privilegiados em instituições de ensino superior de baixa qualidade, inflando diversos empreendimentos beneficiados pelas parcerias público-privadas de financiamento estudantil.

\section{Considerações finais}

No contexto educacional apresentado acima, a Lei 13.415/2017 cumpre seu objetivo de implementar mais uma reforma/rearranjo para o ensino brasileiro visando atender demandas do mercado de trabalho. Isso legitima a progressão da fragmentação e precarização da educação brasileira, a fim de responder às imposições do capital. $\mathrm{O}$ modelo implementado na França deriva de um contexto de possibilidades de escolha para educandos que podem cursar o ensino médio, sendo sua classe social menos influente do que no contexto brasileiro enquanto variável determinante de escolha. Além disso, diferente da proposta brasileira, os franceses optaram por um modelo de ensino técnico que não assume um caráter profissionalizante no que se refere à preparação para o ingresso direto ao mercado de trabalho, 
mas a cursos de ensino superior cujas propostas são direcionadas à formação profissional de forma geral, com ênfase às áreas administrativas.

Isso ocorre porque os países periféricos, como o Brasil, tendem a inserir a classe trabalhadora nos processos produtivos desde a mais tenra idade. Os reflexos desses processos podem ser observados nas diferentes frentes de serviços que deveriam atender aos direitos sociais. $\mathrm{O}$ modelo de ensino direcionado à classe trabalhadora também tem sido utilizado por veículos midiáticos pró-Governo Federal como uma solução para o desemprego estrutural. No entanto, o modelo técnico implementado na educação francesa no ensino médio (Lycée) abrange outro tipo de estrutura social.

O contraste francês com o brasileiro também é evidente nos processos pelos quais a classe trabalhadora perpassa durante sua formação educacional. $O$ ensino que a classe trabalhadora consegue alcançar não lhes dá opção ou oportunidade de escolha: ocorre o ingresso ao curso técnico/profissionalizante ou a um curso superior que perpetua a permanência desse indivíduo na classe social à qual já pertence, mantendo o status quo e reafirmando as questões de mérito.

Quando se pensa na reestruturação de um sistema educacional que apresenta problemas de diversos aspectos, como é observado no sistema educacional brasileiro, é de fundamental importância pensar estrategicamente uma transição, bem como ter clara a capacidade para gerenciar o novo sistema depois de estabelecido. O desprezo do Governo Federal para com a educação brasileira é evidente, e também é possível observar que em âmbito geral a educação está sendo utilizada para a internalização da ideologia capitalista.

\section{REFERÊNCIAS}

BARROS, A. S. X. Expansão da educação superior no brasil: limites e possibilidades.

Educação \& Sociedade, Campinas, v. 36, n. 131, p. 361-390, 2015.

BRANDÃO, C. F. The Basic Education in Sweden and Brazil: some similarities and differences. Educação \& Realidade, v. 44, n. 1, p. 1-19, 2019.

BRASIL. Lei n. 9.394, de 20 de dezembro de 1996. Lei de Diretrizes e Bases da Educação Nacional. Estabelece as diretrizes e bases da educação nacional. Brasília, DF, 23 dez. 1996. Disponível em: https://www2.camara.leg.br/legin/fed/lei/1996/lei-9394-20-dezembro-1996362578-publicacaooriginal-1-pl.html. Acesso em: 10 jun. 2020.

BRASIL. Lei n. 12.711, de 29 de agosto de 2012. Dispõe sobre o ingresso nas universidades federais e nas instituições federais de ensino técnico de nível médio e dá outras providências. Brasília, DF, 30 ago. 2012. Disponível em: http://www.planalto.gov.br/ccivil_03/_ato20112014/2012/Lei/L12711.htm. Acesso em: 10 jun. 2021. 
BRASIL. Lei 13.415, de 16 de fevereiro de 2017. Altera as Leis $\mathrm{n}^{\circ} 9.394$, de 20 de dezembro de 1996, que estabelece as diretrizes e bases da educação nacional, e 11.494, de 20 de junho 2007, que regulamenta o Fundo de Manutenção e Desenvolvimento da Educação Básica e de Valorização dos Profissionais da Educação, a Consolidação das Leis do Trabalho - CLT, aprovada pelo Decreto-Lei $n^{0} 5.452$, de $1^{\circ}$ de maio de 1943, e o Decreto-Lei $n^{\circ} 236$, de 28 de fevereiro de 1967; revoga a Lei $\mathrm{n}^{\mathrm{o}}$ 11.161, de 5 de agosto de 2005; e institui a Política de Fomento à Implementação de Escolas de Ensino Médio em Tempo Integral. Brasília, 17 fev. 2017. Disponível em: http://www.planalto.gov.br/ccivil 03/ ato20152018/2017/lei/113415.htm. Acesso em: 10 jun. 2020.

CONCEIÇÃO, L. B. Em tempos de 'fermentação nascente': uma leitura dos projetos para a instrução pública primária do personagem François Guizot (1832-1836). Revista Brasileira de História da Educação, v. 20, n. 1, p. 1-22, 2020.

CORRÊA, S. S.; GARCIA, S. R. O. “Novo Ensino Médio: Quem conhece aprova!” Aprova? Revista Ibero-Americana de Estudos em Educação, Araraquara, v. 13, n. 2, p. 604-622, 2018.

COULON, A. Le métier d'étudiant : l'entrée dans la vie universitaire. Educação e Pesquisa, São Paulo, v. 43, n. 44, p. 1239-1250, 2017.

FERRETI, C. J.; SILVA, M. R. Reforma do Ensino Médio no contexto da Medida Provisória $n^{\circ}$ 746/2016: estado, currículo e disputas por hegemonia. Educação e Sociedade, Campinas, v. 38, n. 139, p. 385-404, 2017.

FERRETTI, C. J. A reforma do Ensino Médio e sua questionável concepção de qualidade da educação. Estudos Avançados, v. 32, n. 93, p. 25-42, 2018.

FRANCE. Ministère De L'éducation Nationale. L'enseignement scolaire en France. Département des relations européennes et internationales, 2012.

FRANCE. L'accès à l'enseignement supérieur. 2019. Disponível em:

https://publication.enseignementsup-

recherche.gouv.fr/eesr/FR/T943/1_acces_a_1_enseignement_superieur/. Acesso em: 13 jun. 2021.

FRANCE. Les étudiants inscrits dans les universités françaises en 2019-2020. 2020.

Disponível em: https://www.enseignementsup-

recherche.gouv.fr/pid24683/www.enseignementsup-recherche.gouv.fr/pid24683/1-

enseignement-superieur-en-chiffres.html. Acesso em: 13 jun. 2021.

FURTADO, R. S.; SILVA, V. V. A. A reforma em curso no ensino médio brasileiro e a naturalização das desigualdades escolares e sociais. Revista e-Curriculum, São Paulo, v. 18, n. 1, p. 158-179, 2020.

GENDRON, B. Le baccalauréat professionnel comme voie d'accès à l'enseignement supérieur? European Centre for the Development of Vocational Training, v. 46, p. 1-21, 2008 . 
HERNANDES, P. R. A reforma do Ensino Médio e a produção de desigualdades na educação escolar. Revista do Centro de Educação da UFSM, v. 44, p. 1-19, 2019.

IBGE. Instituto Brasileiro De Geografia E Estatística. População. 2021. Disponível em: http://www.ibge.gov.br/apps/populacao/projecao/. Acesso em 05 jun. 2021.

INEP. Instituto Nacional de Estudos e Pesquisas Educacionais Anísio Teixeira. Censo da Educação Superior. 2019. Disponível: https://www.gov.br/inep/pt-br/areas-deatuacao/pesquisas-estatisticas-e-indicadores/censo-da-educacao-superior. Acesso em: 9 jun. 2021.

MELERO, C. et al. A lei $\mathrm{n}^{\circ} 12.711$, de 29 de agosto, como política pública que favorece a busca da igualdade material. Revista de Ciências da Administração, p. 130-142, 2018.

METTETAL, B. Massification et démocratisation de l'accès à l'école et à l'enseignement supérieur. 2020. Disponível: http://ses.ens-lyon.fr/ressources/stats-a-la-une/massification-etdemocratisation-de-lacces-a-lecole-et-a-lenseignement-superieur. Acesso em: 23 jun. 2021.

MOREIRA, L. K. R.; MOREIRA, L. R.; SOARES, M. G. Educação Superior no Brasil: discussões e reflexões. Educação Por Escrito, Porto Alegre, v. 9, n. 1, p. 134-150, 2018.

PEDUZZI, P. Mapa do Ensino Superior aponta maioria feminina e branca. 2020.

Disponível em: https://agenciabrasil.ebc.com.br/educacao/noticia/2020-05/mapa-do-ensinosuperior-aponta-para-maioria-feminina-e-branca. Acesso em: 10 jun. 2021.

PELLET, S. École publique, école privée : une comparaison. La Découverte | « Regards croisés sur l'économie », v. 12, n. 2, p. 184-188, 2012.

PIOLLI, E.; SALA, M. Reforma do ensino médio e a educação profissional: da Lei de Diretrizes e Bases (LDB) às Diretrizes Curriculares Nacionais para o Ensino Médio e para a Educação Profissional. Revista Exitus, Santarém, v. 11, p. 01-25, 2021.

POPULATION DATA. République française. 2021. Disponível em: https://www.populationdata.net/pays/france/amp/. Acesso em: 5 jun. 2021.

PROST, A. Reflexões sobre o modelo de ensino francês. Pro-Posições, Unicamp, v. 15, n. 2, p. 151-162, 2004.

ROSAR, M. F. F. Educação e Movimentos Sociais: avanços e recuos entre o século XX e o século XXI. Educação em Revista, Marília, v. 12, n. 2, p. 145-162, 2011. 


\section{Como referenciar este artigo}

GOMES, M. C. O.; SAMPAIO, M. G. O Ensino Médio no Brasil e na França: considerações sobre a Lei 13.415/2017 a partir de uma análise comparativa. Revista on line de Política e Gestão Educacional, Araraquara, v. 25, n. esp. 4, p. 2066-2079, dez. 2021. e-ISSN:15199029. DOI: https://doi.org/10.22633/rpge.v25iesp.4.15940

Submetido em: 20/08/2021

Revisões requeridas em: 12/10/2021

Aprovado em: $15 / 11 / 2021$

Publicado em: 08/12/2021 